\title{
Proof Loading and Structural Reliability
}

\author{
Tzyy Shan Lin \\ Department of Civil Engineering, Johns Hopkins University, \\ Baltimore, Maryland, USA \\ and \\ Andrzej S. Nowak \\ Department of Civil Engineering, University of Michigan, \\ Ann Arbor, Michigan 48109, USA
}

(Received: 8 June, 1983)

\begin{abstract}
Structural reliability depends on uncertainties in resistance and loads. In many practical cases the resistance dominates and a reduction of uncertainty about resistance is an effective way of increasing safety. It can be accomplished by proof loading.

$A$ truncated distribution is considered and reliability indices are calculated for various proof load levels. The structural reliability is sensitive to proof loading for larger coefficients of variation of resistance.

A Bayesian approach is applied to develop a posterior distribution for resistance, after proof loading. Reliability indices are calculated for various ratios of the coefficients of variation of load and resistance.
\end{abstract}

\section{NOTATION}

$A_{i} \quad$ Parameter in Bayesian formula

$F \quad$ Cumulative distribution function

$f \quad$ Probability density function

$P \quad$ Probability

Reliability Engineering 0143-8174/84/\$03.00 (C) Elsevier Applied Science Publishers Ltd, England, 1984. Printed in Great Britain 


$\begin{array}{ll}p & \text { Non-dimensional proof load } \\ P_{\mathrm{F}} & \text { Probability of failure } \\ Q & \text { Load effect } \\ q & \text { Reduced variable, load effect } \\ Q_{\mathrm{P}} & \text { Proof load } \\ R & \text { Resistance } \\ r & \text { Reduced variable, resistance } \\ R^{\prime} & \text { Variable representing objective uncertainties in } R \\ S & \text { Variable representing subjective uncertainties in } R \\ S & \text { Realization of } S \\ X_{i} & \text { Variable representing result of proof loading } \\ X_{i}^{\prime} & \text { Survival of the } i \text { th consecutive proof loading } \\ X_{i}^{\prime \prime} & \text { Failure at the } i \text { th consecutive proof loading } \\ \beta & \text { Reliability index } \\ \phi & \text { Central safety factor } \\ \Phi & \text { Standard normal distribution function } \\ \sigma & \text { Standard deviation }\end{array}$

Subscripts

$Q \quad$ Load effect

$q \quad$ Reduced variable, load effect

$R \quad$ Resistance

$r \quad$ Reduced variable, resistance

Superscripts

Mean value

* Truncated distribution or its parameter

\section{INTRODUCTION}

Structural safety is a function of the relation between the resistance, $R$, and load effect, $Q$. The structure performs its function as long as $R$ is not less than $Q$, and probability of failure, $P_{F}$, is:

$$
P_{\mathrm{F}}=P(R<Q)
$$

If the cumulative distribution function (CDF) for $R$ is $F_{R}$, and for $Q$ it is $F_{Q}$, then:

$$
P_{\mathrm{F}}=\int_{-\infty}^{\infty} F_{R}(x) \mathrm{d} F_{Q}(x) \mathrm{d} x
$$


or

$$
P_{\mathrm{F}}=1-\int_{-\infty}^{\infty} F_{Q}(x) \mathrm{d} F_{R}(x) \mathrm{d} x
$$

In practice, a direct use of eqns. (2) and (3) is rather limited because of numerical difficulties. Instead, safety can be measured in terms of a reliability index, $\beta$, as defined by Cornell ${ }^{2}$ and modified by Hasofer and Lind. ${ }^{5}$ The relationship between $\beta$ and $P_{\mathrm{F}}$ is:

$$
P_{\mathrm{F}}=\Phi(-\beta)
$$

where $\Phi$ is the standard normal CDF.

If both $R$ and $Q$ are independent and normal random variables, then:

$$
\beta=(\bar{R}-\bar{Q}) /\left(\sigma_{R}^{2}+\sigma_{Q}^{2}\right)^{1 / 2}
$$

where $\bar{R}$ and $\sigma_{R}$ are the mean and standard deviation, respectively, of $R$; and $\bar{Q}$ and $\sigma_{Q}$ are the mean and standard deviation, respectively, of $Q$.

If both $R$ and $Q$ are independent and lognormal random variables, then:

$$
\beta=\ln (\bar{R} / \bar{Q}) /\left(V_{R}^{2}+V_{Q}^{2}\right)^{1 / 2}
$$

where $V_{R}$ and $V_{Q}$ are coefficients of variation of $R$ and $Q$, respectively. In eqn. (6) it is assumed that $\overline{\ln R}=\ln \bar{R}, \overline{\ln Q}=\ln \bar{Q}, \ln \left(1+V_{R}\right)=V_{R}$ and $\ln \left(1+V_{Q}\right)=V_{Q}$.

If $R$ or $Q$ are neither normal nor lognormal, then $\beta$ can be calculated using a procedure suggested by Rackwitz and Fiessler. ${ }^{9}$ The method is based on normal approximations of non-normal distributions at the socalled design point.

In practical cases the structural reliability depends mostly on the lower tail of $F_{R}$ and on the upper tail of $F_{Q}$. Better knowledge of these tails may allow for an increase in $\beta$.

Proof loading may provide additional knowledge about resistance. For example, a structure which survives a certain load may be considered as more reliable than one which has never been exposed to such a load. Recently Grigoriu and Lind $^{4}$ and Madsen and Lind $^{6}$ developed probabilistic models for prototype testing of series-produced structures. This paper deals with evaluation of the effect of proof loading on structural reliability. The distribution of resistance, truncated at the proof load level, is considered first. Then Bayesian approach is used to develop a posterior distribution. 


\section{RESISTANCE AND LOAD MODELS}

The distributions of resistance have been established on the basis of tests, engineering experience and judgement. For typical structures, the coefficients of variation are given in Table 1 after Ellingwood et al. ${ }^{3}$ The values of $V_{R}$ vary from $8 \%$ for pretensioned concrete beams to over $20 \%$ for masonry walls.

Load, $Q$, can be considered as a combination of various components (dead load, live load, environmental loads, etc.). Load models were presented by Ellingwood et al. ${ }^{3}$ and Nowak and Lind. ${ }^{7,8}$ Coefficients of variation for the total load effect are between 10 and $20 \%$; they are larger in special cases.

The relationship between nominal load and nominal resistance is

TABLE I

Coefficients of Variation of Resistance (after Ellingwood $e t$ al. ${ }^{3}$ )

\begin{tabular}{|c|c|c|}
\hline $\begin{array}{c}\text { Material } \\
I\end{array}$ & $\begin{array}{c}\text { Member } \\
2\end{array}$ & $V_{R}$ \\
\hline Structural steel & $\begin{array}{l}\text { Tension members } \\
\text { Compact beam, flexure } \\
\text { Beam-column } \\
\text { Plate girder, flexure } \\
\text { Axially loaded column } \\
\text { A325 high-strength bolt, tension }\end{array}$ & $\begin{array}{r}11 \\
13 \\
15 \\
12 \\
14 \\
9\end{array}$ \\
\hline Cold-formed steel & $\begin{array}{l}\text { Braced beams with stiffened flanges } \\
\text { Columns with stiffened flanges }\end{array}$ & $\begin{array}{l}17 \\
20\end{array}$ \\
\hline Reinforced concrete & $\begin{array}{l}\text { Flexure grade } 40 \\
\text { Flexure, grade } 60 \\
\text { Flexure, pretensioned beams } \\
\text { Flexure, post-tensioned beams } \\
\text { Short column, compression failure } \\
\text { Short column, tension failure } \\
\text { Slender column, compression failure } \\
\text { Slender column, tension failure } \\
\text { Shear, no stirrups } \\
\text { Shear, minimum stirrups }\end{array}$ & $\begin{array}{l}14 \\
11 \\
8 \\
9 \cdot 5 \\
16 \\
12 \\
17 \\
12 \\
21 \\
19\end{array}$ \\
\hline Masonry walls & $\begin{array}{l}\text { Concrete, inspected } \\
\text { Concrete, uninspected } \\
\text { Brick, inspected } \\
\text { Brick, uninspected }\end{array}$ & $\begin{array}{l}19 \\
21 \\
18 \\
21\end{array}$ \\
\hline
\end{tabular}


established by the code. For a given load, $Q$, the required resistance is specified. The central safety factor, $\theta$, can be calculated knowing the mean-to-nominal ratios for $R$ and $Q$. For typical cases, $\theta$ is about 3.0. In further analysis, both $R$ and $Q$ are assumed to be lognormally distributed and $\theta=\bar{R} / \bar{Q}=3 \cdot 0$.

\section{PROOF LOADING}

Loading of a structure can be considered as a test. The result is either survival or partial or total failure. The load may be a service load (dead load, live load or environmental load) or a specially imposed test load. In both cases the proof load level, $Q_{\mathrm{p}}$, can be considered as the lower bound on $F_{R}$, so that $F_{R}(x)=0$, for $x \leq Q_{\mathrm{p}}$.

The reliability of structures surviving a proof load, $Q_{\mathrm{p}}$, is considered using two models for $F_{R}$ : a truncated distribution and a posterior Bayesian distribution.

\subsection{Truncated distribution analysis}

Let $f_{R}$ be the probability density function of resistance prior to proof loading. For a structure which has survived the load $Q_{p}$ the density can be changed into a truncated function:

$$
f_{R}^{*}(x)= \begin{cases}f_{R}(x) /\left(1-F_{R}\left(Q_{\mathrm{p}}\right)\right) & \text { for } x>Q_{\mathrm{p}} \\ 0 & \text { for } x \leq Q_{\mathrm{p}}\end{cases}
$$

Examples of $f_{R}$ and $f_{R}^{*}$ are shown in Fig. 1 .

The reliability index for the structure prior to proof loading is given by eqn. (6). For a truncated distribution of $R, \beta$ is equal to the distance from the failure boundary $(R-Q=0)$ to the origin in the space of reduced variables.

Let $r$ and $q$ be the reduced variables, such that:

$$
r=\ln (R / \bar{R}) / V_{R}
$$

and

$$
q=\ln (Q / \bar{Q}) / V_{Q}
$$

Then the failure boundary in terms of $r$ and $q$ is:

$$
r V_{R}+\ln \bar{R}-q V_{Q}-\ln \bar{Q}=0
$$




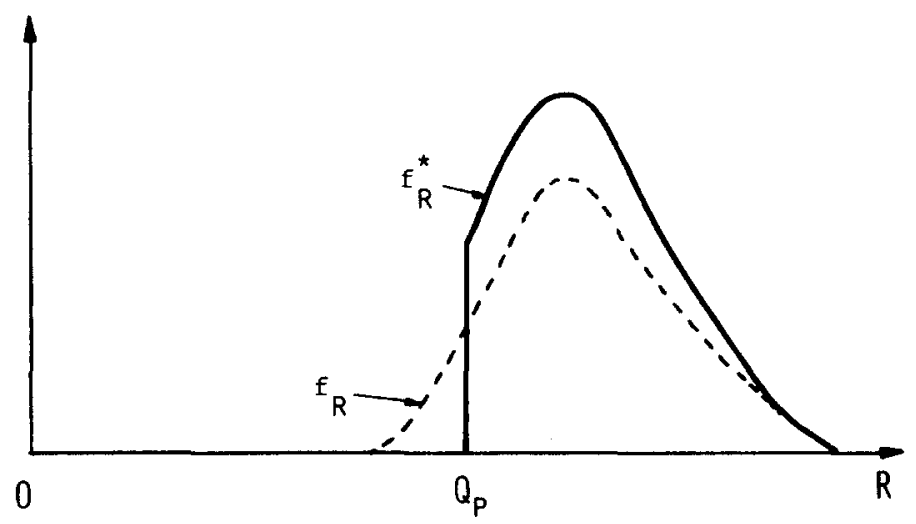

Fig. 1. Probability density function of resistance prior to proof loading and after surviving the proof loading, $Q_{\mathbf{p}}$.

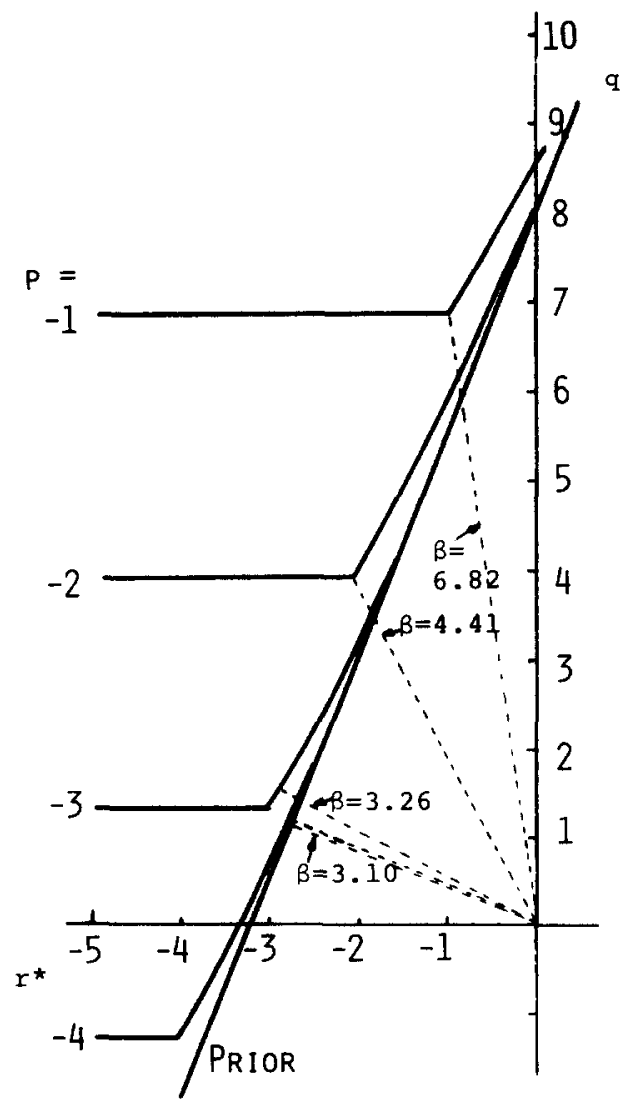

Fig. 2. Failure boundaries in reduced space for $V_{R} / V_{Q}=2.5$ and various levels of proof loading. 


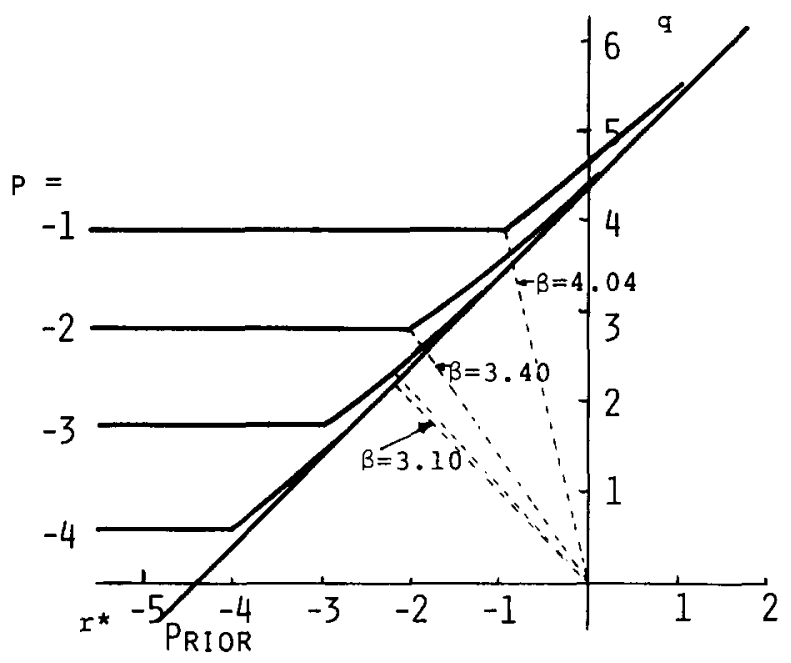

Fig. 3. Failure boundaries in reduced space for $V_{R} / V_{Q}=1.0$ and various levels of proof loading.

The proof load, $Q_{\mathrm{p}}$, can be expressed, non-dimensionally, as:

$$
p=\ln \left(Q_{\mathrm{p}} / \bar{R}\right) / V_{R}
$$

The truncated probability density function (eqn. (7)), becomes:

$$
f_{r}^{*}(x)= \begin{cases}\frac{1}{\sqrt{(2 \pi)}} \exp \left(-\frac{x^{2}}{2}\right) /(1-\Phi(p)) & \text { for } x>p \\ 0 & \text { for } x \leq p\end{cases}
$$

The reliability index corresponding to $f_{r}^{*}$ is calculated as a generalization of the Hasofer-Lind ${ }^{5}$ definition. A non-linear transformation of $r$ to a new reduced Gaussian variable, $r^{*}$, is made, so that:

$$
r^{*}=\Phi^{-1}\left[\frac{\Phi(r)-\Phi(p)}{1-\Phi(p)}\right] \quad \text { for } r \geq p
$$

Thus the failure region in the Gaussian probability space is transformed into:

$$
\Phi^{-1}\left\{\Phi\left(r^{*}\right)[1-\Phi(p)]+\Phi(p)\right\} V_{R}+\ln \bar{R}-q V_{Q}-\ln \bar{Q}<0
$$

In two-dimensional space $(r, q)$, the boundary of that region is plotted for the ratios $V_{R} / V_{Q}=2.4,1.0$ and 0.4 in Figs. 2,3 and 4, respectively. Four values of non-dimensional proof load are considered: $p=-1,-2,-3$ 


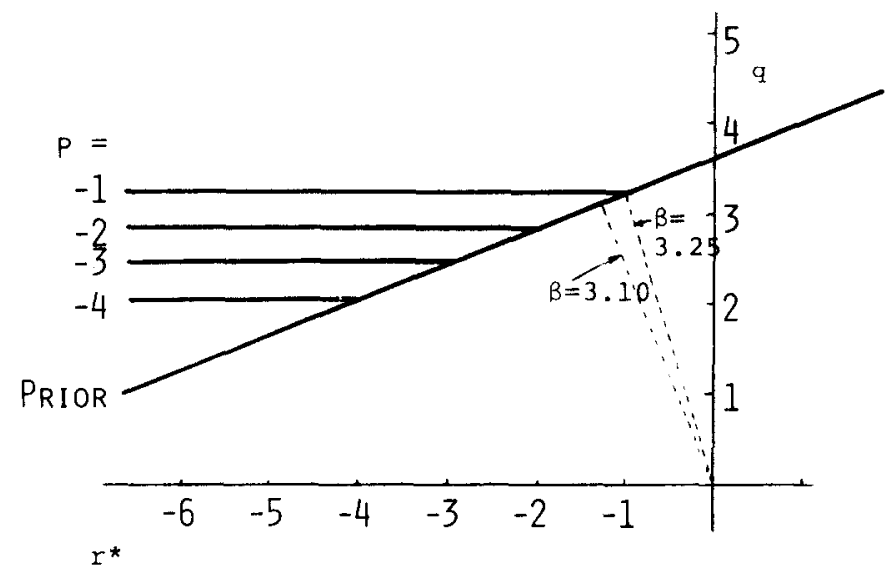

Fig. 4. Failure boundaries in reduced space for $V_{R} / V_{Q}=0.4$ and various levels of proof loading.

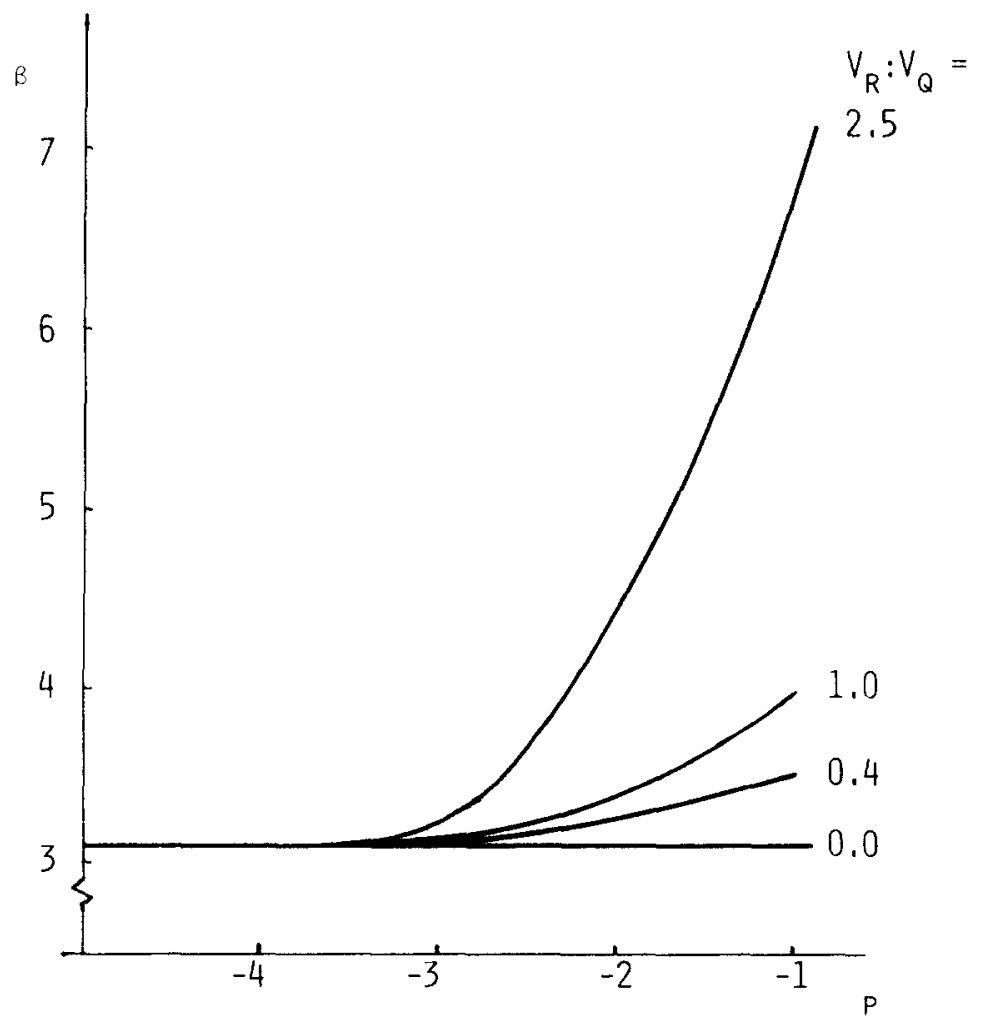

Fig. 5. Reliability indices v. proof load level. 
and -4 . For comparison, the failure region boundary prior to proof loading is also plotted. The reliability index is a norm of the failure region given by the above inequality.

Reliability indices were calculated using a specially developed computer program. The value of $V_{R}$ is selected so that prior to proof loading the reliability index is $\beta=3 \cdot 10$. The results of calculations are shown in Figs. 2, 3 and 4. In Fig. 5, $\beta$ values are plotted v. nondimensional proof load level $p$ (in the reduced space). As expected, proof loading is most effective for cases with larger $V_{R} / V_{Q}$ ratios. For $V_{R} / V_{Q}=0 \cdot 4$, to increase $\beta$ by $20 \%$ a proof load equal to $\bar{R}$ is required $(p=0)$. But then the chance of survival of the test is reduced to about $50 \%$.

\subsection{Bayesian approach}

Uncertainties in resistance can be classified as objective or subjective. The objective uncertainties are those that are measurable, for example dimensions or strength of material. The subjective uncertainties are those which pertain to the designer's judgement or intuition. The resistance can be considered as a product of two variables:

$$
R=S R^{\prime}
$$

where $R^{\prime}$ is a variable representing the objective uncertainty in $R$ and $S$ is a corrective factor introduced to count for imperfections in the predicted model (subjective uncertainties). In the following analysis the Bayesian approach is used to reduce the variation in $S$ by proof loading.

The probability conditional on experimental results (proof loading) can be given by the well-known Bayesian formula: ${ }^{1}$

$$
P\left(A_{i} \mid X\right)=\frac{P\left(X \mid A_{i}\right) P\left(A_{i}\right)}{\sum_{i=1}^{m}\left[P\left(X \mid A_{j}\right) P\left(A_{j}\right)\right]}
$$

where $A_{i}$ is one of the possible cases or parameter values, $A_{1} \cup \cdots \cup A_{m}$ is the total space, $A_{i} \cap A_{j}$ is $\varnothing$ for any $i \neq j, P\left(A_{i}\right)$ is the prior probability of $A_{i}, X$ is experimental or observed data and $P\left(A_{i} \mid X\right)$ is the posterior probability of $A_{i}$.

If the parameter $A$ varies continuously, then the sum in eqn. (15) can be 


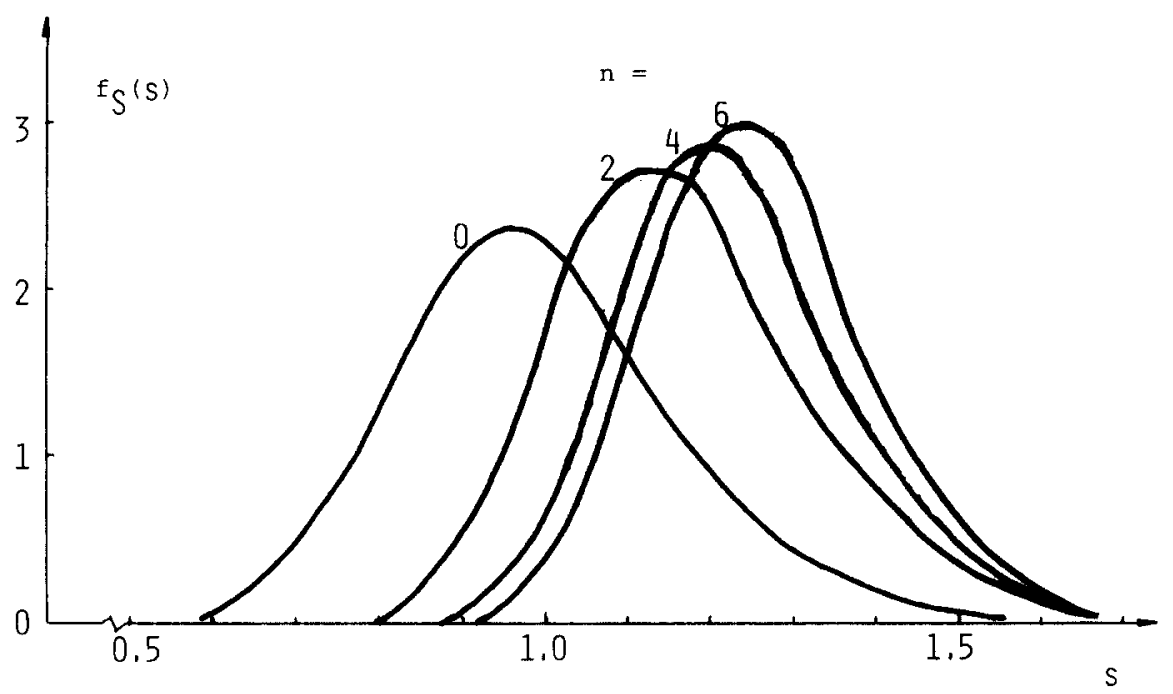

Fig. 6. Probability density functions of $S$ : prior $f_{S}$, and posterior $f_{S}^{\prime \prime}, f_{S}^{(4)}$ and $f_{S}^{(6)}$.

replaced by an integral. And so for the corrective factor $S$ in eqn. (14) the posterior density function becomes:

$$
f_{S}^{\prime}(s)=\frac{P(X \mid S) f_{S}(s)}{\int_{-\infty}^{\infty} P(X \mid S) f_{S}(s) \mathrm{d} s}
$$

where $f_{S}(s)$ is the prior density function of $S$.

The structure may be subjected to a series of proof loads. If $X_{1}, X_{2}, \ldots, X_{n}$ denotes consecutive test data, then the posterior density function, $f_{S}$, can be modified as follows:

$$
\begin{gathered}
f_{S}^{\prime \prime}(s)=\frac{P\left(X_{1} \mid S\right) f_{S}(s)}{\int_{-\infty}^{\infty} P\left(X_{1} \mid S\right) f_{S}(s) \mathrm{d} s} \\
f_{S}^{\prime \prime}(s)=\frac{P\left(X_{2} \mid S\right) f_{S}^{\prime}(s)}{\int_{-\infty}^{\infty} P\left(X_{2} \mid S\right) f_{S}^{\prime}(s) \mathrm{d} s} \\
\vdots \\
f_{S}^{(n)}(s)=\frac{P\left(X_{n} \mid S\right) f_{S}^{(n-1)}(s)}{\int_{-\infty}^{\infty} P\left(X_{n} \mid S\right) f_{S}^{(n-1)}(s) \mathrm{d} s}
\end{gathered}
$$

$X_{i}$ in eqn. (17) is the result of the $i$ th application in a series of $n$ proof loads. Two events are considered: the structure survives the proof load or fails. Let $X_{i}^{\prime}$ denote survival and $X_{i}^{\prime \prime}$ denote failure. Then the conditional 


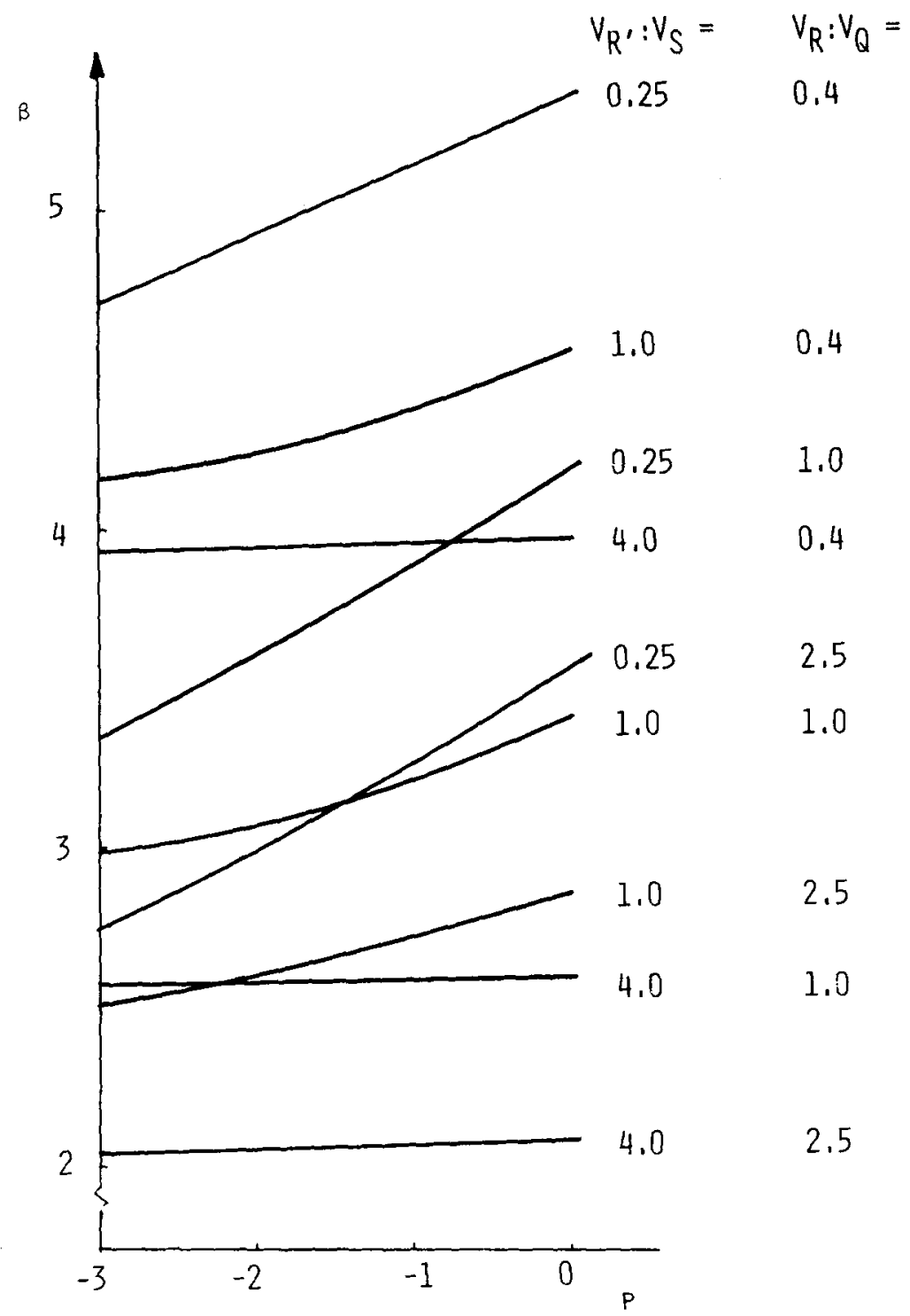

Fig. 7. Reliability indices v. proof load level, for one application of proof load. 


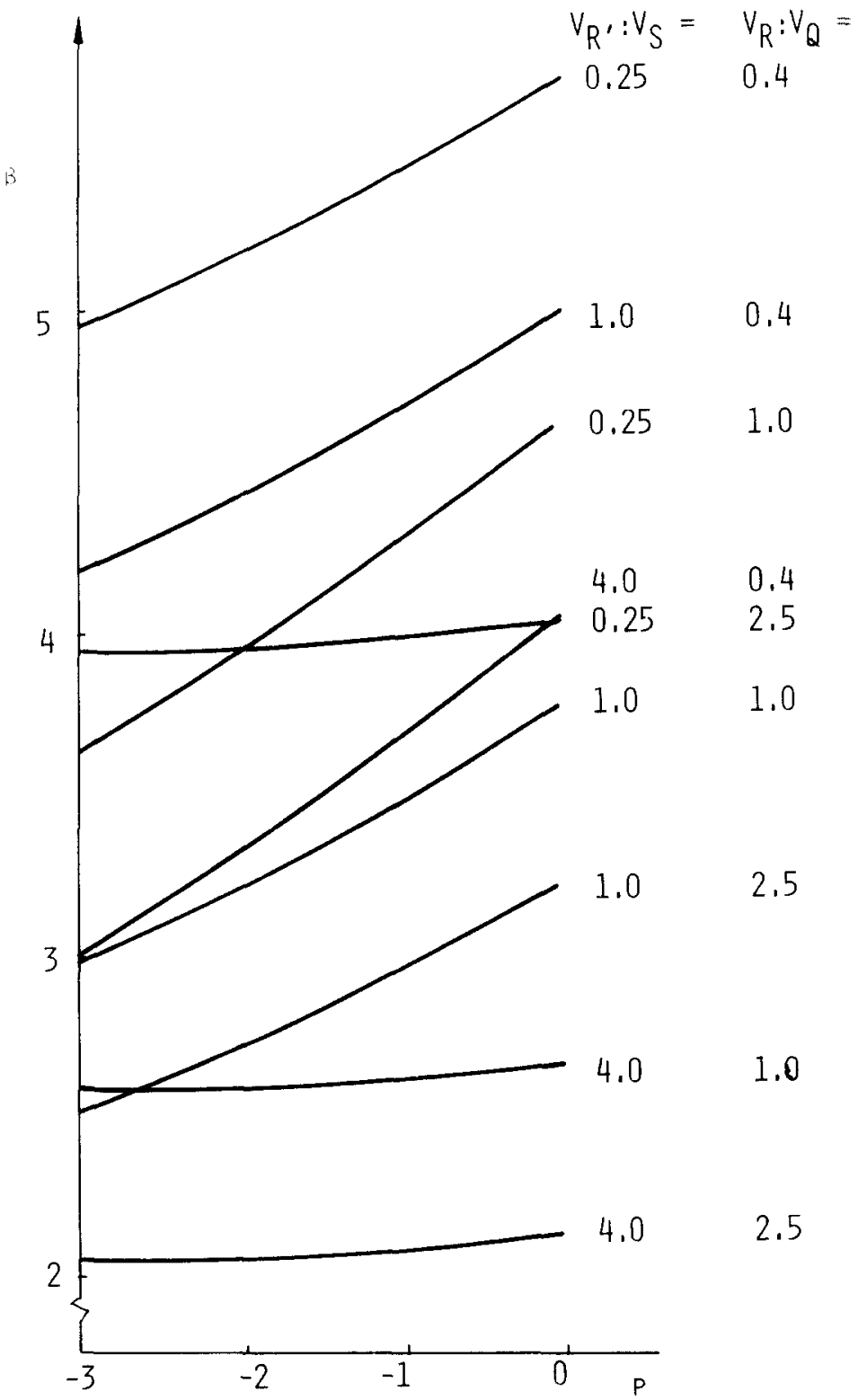

Fig. 8. Reliability indices $v$. proof load level, for five applications of proof load. 


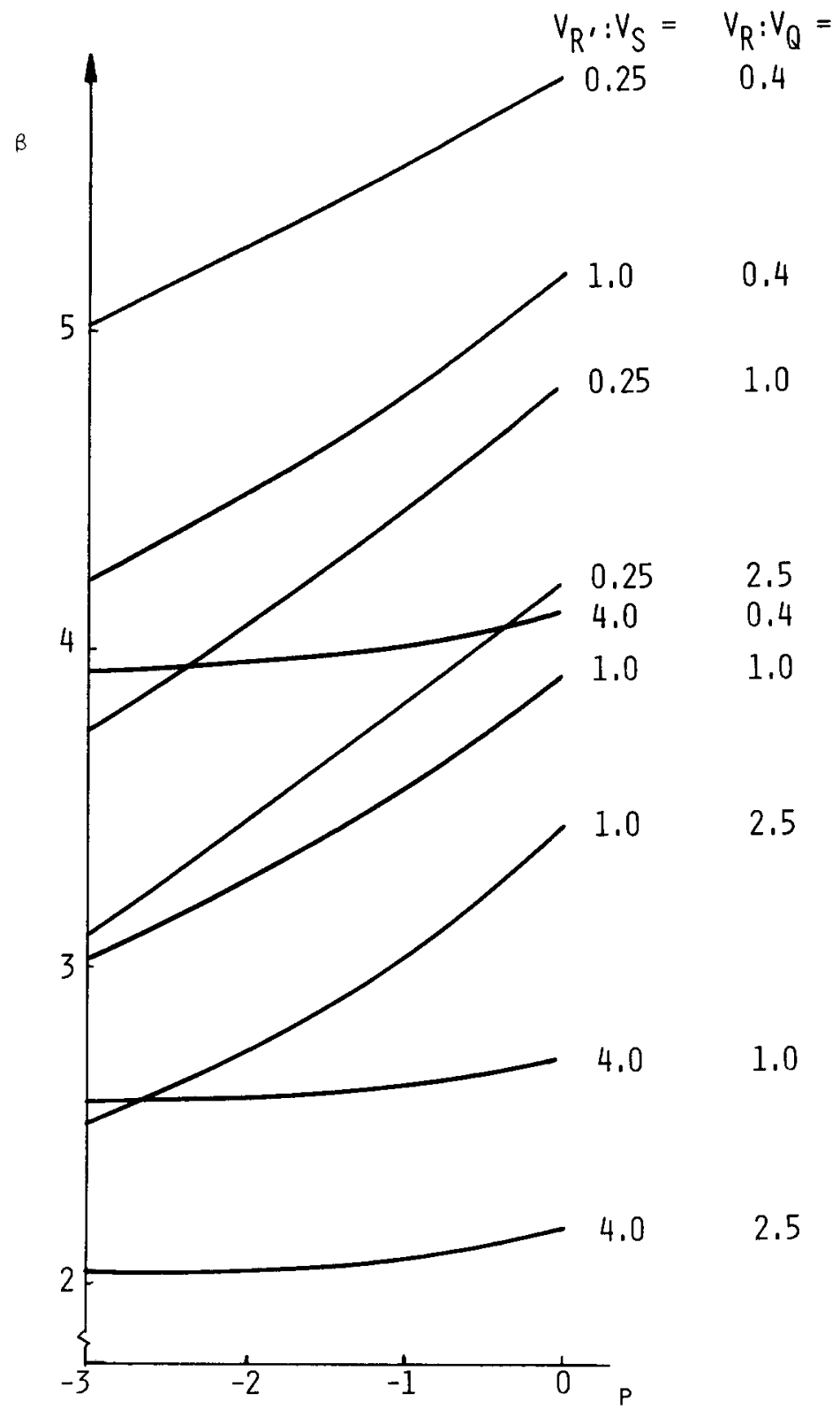

Fig. 9. Reliability indices v. proof load level, for 10 applications of proof load. 


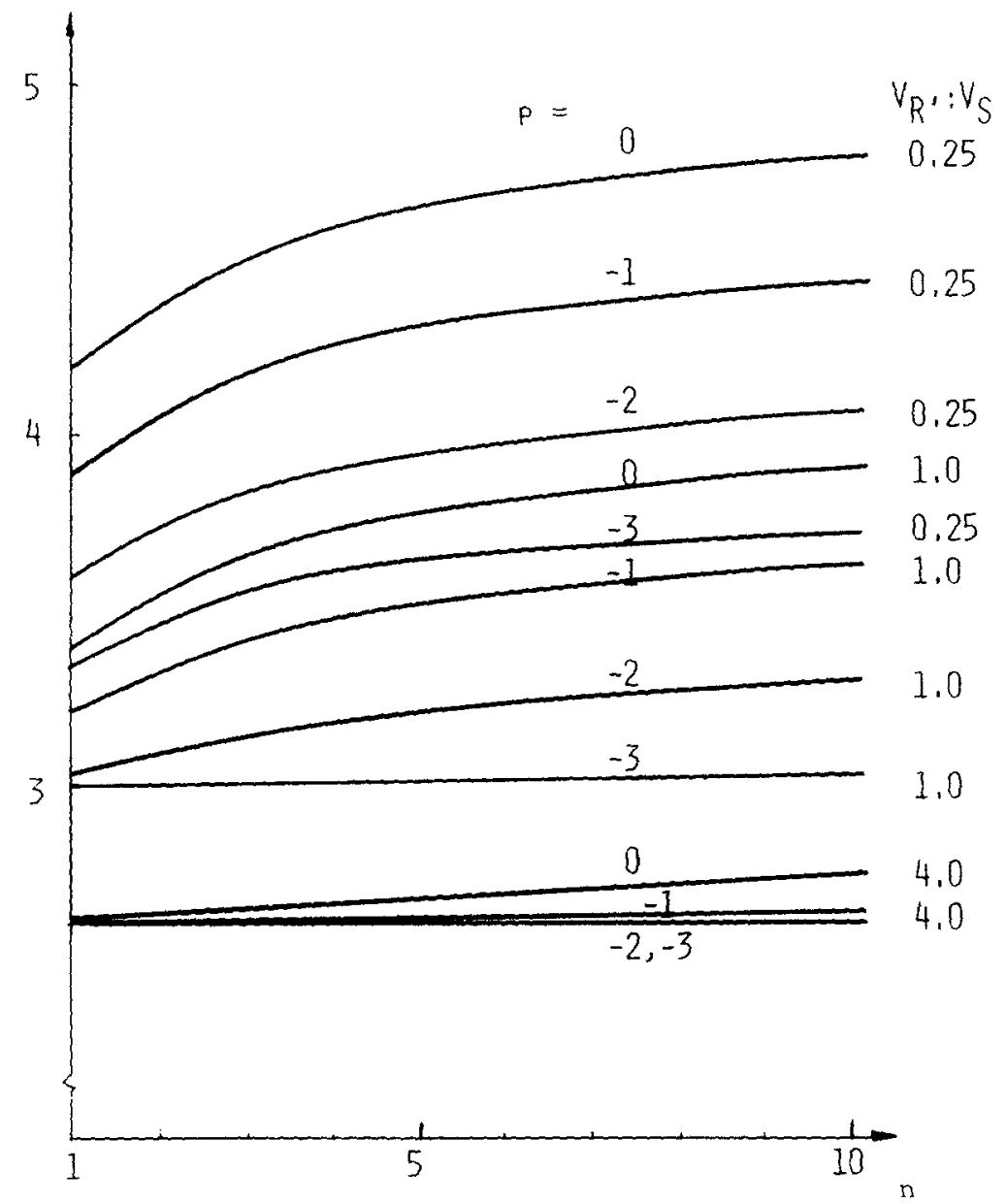

Fig. 10. Reliability indices $v$. number of applications of proof load for $V_{R} / V_{Q}=1 \cdot 0$.

probabilities in eqn. (17) can be derived as follows. Probability of survival of proof load, $Q_{p}$, is:

$$
P\left(X_{i}^{\prime} \mid s\right)=P\left(S R^{\prime} \geq Q_{\mathrm{p}} \mid S=s\right)
$$

For $S$ and $R^{\prime}$ lognormal, eqn. (18) becomes:

$$
\left.P\left(X_{i}^{\prime} \mid s\right)=1-\Phi\left[\left(\ln Q_{\mathfrak{p}}-\ln (s \bar{R})\right) / V_{R^{\prime}}\right)\right]
$$

Proof load level can be expressed as a non-dimensional parameter, $p$, equal to:

$$
p=\left(Q_{\mathrm{p}}-\bar{R}^{\prime}\right) / \sigma_{R^{\prime}}
$$


Then $Q_{\mathrm{p}}$ can be calculated from eqn. (20) and it can be replaced in eqn. (19). After transformation, eqn. (19) becomes:

$$
P\left(X_{i}^{\prime} \mid s\right)=\Phi\left[\ln \left(\frac{s}{1+p V_{R^{\prime}}}\right) / V_{R^{\prime}}\right]
$$

Similarly, the probability of failure at proof load, $Q_{\mathrm{p}}$, is:

$$
P\left(X_{i}^{\prime \prime} \mid s\right)=\Phi\left[\ln \left(\frac{1+p V_{R}^{\prime}}{s}\right) / V_{R^{\prime}}\right]
$$

For the posterior density functions the reliability indices were calculated using the Rackwitz and Fiessler procedure. ${ }^{9}$ Three ratios of $V_{R^{\prime}}$ to $V_{Q}$ were considered: $2 \cdot 5,1 \cdot 0$ and 0.4 , and three ratios of $V_{R^{\prime}}$ to $V_{S}$ : $4 \cdot 0,1 \cdot 0$ and $0 \cdot 25$.

In Fig. 6 the posterior densities, $f_{S}$, are plotted for various numbers of proof loadings, $n$. In Figs. 7-9 the reliability indices are plotted v. proof load level for various $n, V_{R^{\prime}}, V_{S}$ and $V_{Q}$ ratios. In Fig. $10 \beta$ values are plotted v. $n$.

Structural reliability can be significantly improved by proof loading in the cases when $V_{S}$ is larger than or equal to $V_{R^{\prime}}$. The reliability indices are less sensitive to the ratio of $V_{R}$, to $V_{Q}$.

\section{CONCLUSIONS}

In practical cases, the variation of resistance dominates structural reliability. The distribution of resistance may be improved by proof loading; a structure which survives a certain load can be considered as more reliable than one which has never been exposed to load.

A truncated distribution function was assumed for resistance of a structure which survived a proof load. Reliability indices were calculated for various ratios of the coefficient of variation of resistance and load. For low ratios of $V_{R}$ to $V_{Q}$ the proof loading is ineffective, and regardless of the proof load level, as shown in Fig. 5.

Uncertainty in resistance for objective and subjective reasons is considered. Proof loading has been used to reduce subjective uncertainties on the basis of a Bayesian approach. Reliability indices have been calculated for a series of proof load applications, various ratios of coefficients of variation $V_{R^{\prime}}, V_{S}$ and $V_{Q}$ for various proof load levels. Values of $\beta$ are more sensitive to the ratio of $V_{R^{\prime}} / V_{S^{\prime}}$ than to $V_{R^{\prime}} / V_{Q^{\prime}}$. 


\section{REFERENCES}

1. Benjamin, J. R. and Cornell, C. A. Prohability, Statistics, and Decisions for Civil Engineers, McGraw-Hill Book Co. Inc., New York, 1970.

2. Cornell, C. A. Structural Reliability and Codified Design, Ed. N.C. Lind, S.M. Study No. 3, Solid Mech. Div., University of Waterloo, Ontario, 1970.

3. Ellingwood, B. et al. Development of a Probability Based Load Criterion for American National Standard A58, National Bureau of Standards, Special Publication 577, Washington DC, June 1980.

4. Grigoriu, M. and Lind, N. C. Probabilistic models for prototype testing, $J$. St. Div., ASCE, 108(ST7) (July 1982), pp. 1511-25.

5. Hasofer, A. M. and Lind, N. C. An exact and invariant first-order reliability format, J. Eng. Mech. Div., ASCE, 100(EM1) (January 1974), pp. 111-21.

6. Madsen, P. H. and Lind, N. C. Bayesian approach to prototype testing, J. St. Div., ASCE, 108(ST4) (April 1982), pp. 753-69.

7. Nowak, A. S. and Lind, N. C. Practical code calibration procedures, Can. J. Civil Eng. (6) (June 1979), pp. 112 19.

8. Nowak, A. S. and Lind, N. C. Practical bridge code calibration, J. St. Div., ASCE, 105(ST12) (December 1979), pp. 2497-510.

9. Rackwitz, R. and Fiessler, B. Structural reliability under combined random load sequences, Comp. Struct. (9) (1978), pp. 484-94. 